\title{
Las dos caras de una misma moneda. Reformismo y esclavitud en Santo Domingo a fines del periodo colonial ${ }^{1}$
}

\author{
por \\ José Luis Belmonte Postigo \\ Universidad Pablo de Olavide
}

\begin{abstract}
El proyecto reformista borbónico articuló una serie de medidas que pretendían el incremento del esclavismo en el área del Caribe. Una de estas medidas fue la creación de una normativa legal unitaria que estableciera de manera formal el marco de relaciones entre propietarios y esclavos. Su implementación fracasó, en buena medida, porque se alejaban del ámbito de las costumbres que habian regido las relaciones amo-esclavo en Santo Domingo durante buena parte del periodo colonial.
\end{abstract}

Palabras Clave: Reformismo Borbónico; leyes; costumbres; esclavitud.

El 23 de septiembre de 1775, un Escribano de Cámara de la Audiencia de Santo Domingo se personó ante el cabildo de la ciudad para reclamar la entrega de las Ordenanzas sobre esclavos, cuyos trabajos habían comenzado en mayo de 1768. El cabildo entregó la documentación requerida, un total de nuevas hojas, lo que exasperó al Fiscal de la Audiencia Martínez de Arraque. En enero de ese mismo año ya había tomado una resolución semejante para comprobar que, en los casi siete años precedentes, y a pesar de la advertencia de la extrema urgencia con la que había que terminar la redacción de la normativa, sólo se habían redactado tres pliegos y medio. Martínez de Arraque calificó la demora como injustificada y provocada por el propio cabildo, reclamó que se apercibiese a los culpables de tanta desidia, tomó la documentación y, el 9 de octubre de ese mismo año terminó la redacción de su repre-

${ }^{1}$ Queremos agradecer a los profesores Tristan Platt y Jorge Gelman la lectura previa que realizaron de éste trabajo, así como sus comentarios y sugerencias. 
sentación, en la que solicitaba se eliminaran buena parte de las referencias a las ordenanzas del siglo XVI que seguían vigentes. La Audiencia pasó la documentación a D. Joseph Guridi, abogado del cabildo, para su adecuación a los requerimientos del Fiscal, y allá quedó guardada en alguna gaveta, ya que no se produjo el menor adelanto en el trabajo en los ocho años siguientes, cuando fueron utilizados como documentos de trabajo para la elaboración del código negro carolino ${ }^{2}$.

Las nuevas ordenanzas, conocidas coma la Ordenanzas de Santo Domingo de 1768, primer intento en el mundo hispánico por establecer un código legal unitario para el conjunto de las posesiones hispanas, pretendían subvertir buena parte de las costumbres que habían articulado las relaciones entre amos y esclavos en la colonia. Recortaba los ámbitos en los que podían desarrollarse el esclavo sin permiso de su propietario, dificultaba su acceso a la libertad y revitalizaba el papel de las instituciones políticas de carácter local como garantes del buen cumplimiento de la normativa. La laxitud del sistema legal ofrecía, hasta esa fecha, una serie de resquicios que tanto propietarios como esclavos pretendieron aprovechar, si bien no en el mismo grado. Así, los propietarios manipularon las leyes esclavistas para establecer un dominio más severo, tratar de re-esclavizar a libertos o captar siervos de otros propietarios, entre otro tipo de acciones. Como contraposición, algunos esclavos interpretaron el conjunto de regulaciones legales $\mathrm{y}$, amparados por ciertas prácticas sociales, establecieron estrategias de resistencia a los abusos de los amos, consiguiendo mejorar, en ocasiones, sus condiciones de vida, tratando de preservar, en la medida de lo posible, los espacios de libertad que los vacíos de la normativa legal, y la costumbre, les había posibilitado ${ }^{3}$. Todo ello en un contexto en el que las autoridades coloniales pretendieron normativizar las condiciones de servidumbre, intentando establecer un nuevo espacio de relaciones que confrontaba con las prácticas sociales vigentes. El proyecto esclavista borbónico requería de la elaboración de un conjunto de leyes que homogeneizara el aluvión de disposiciones de tipo local, que en la práctica, regulaban el marco de la esclavitud en las posesiones hispanas, por lo que se establecieron diferentes proyectos, como las ordenanzas de Santo Domingo de 1768 o el código negro carolino de 1789, para tal fin, si bien ninguna de estas disposiciones fueron finalmente llevadas a cabo.

2 Lucena Salmoral, 2000: 300-301.

3 Belmonte Postigo, 2013: 65-92. 
ESCLAVITUD Y LEY

La esclavitud, entendida como institución jurídica, era conocida en Castilla desde la Antigüedad y articulada desde la época medieval por Las leyes de las Sietes partidas, recopilación legal elaborada en tiempos de Alfonso X que recogía buena parte de la tradición germano-romana. Para Franklin Knight, en el propio sustrato de la redacción de éste código legal aparecen elementos que parecen condenar la práctica del esclavismo, al considerarlo como «la más vil y más despreciable cosa que puede existir entre los hombres» ${ }^{4}$ aunque este juicio moral no significó una apuesta clara por la destrucción de la institución. La esclavitud bajomedieval tenía unas características esencialmente urbanas y la legislación articulada para su regulación estaban enmarcadas en una sociedad señorial ${ }^{5}$. Si bien sentó las bases teóricas sobre las que se fundamentó parte de las relaciones entre amo y esclavo ${ }^{6}$, para entender en la práctica el desarrollo esclavista en la América española, frecuentemente hay que dejar a un lado las consideraciones legales que marcaban las leyes de las Siete Partidas7, a pesar de que en ocasiones, cuando trataron de ser revocadas, los propios esclavos reclamaron su permanencia, ya que les ofrecían una mínima garantía jurídica ${ }^{8}$.

A ello debemos añadir que desde los primeros años de la colonización castellana en Santo Domingo, donde se experimentó un rápido tránsito a modelos de plantación trabajados con mano de obra esclava, se redactaron, desde el cabildo, una serie de ordenanzas destinadas a regular las nuevas condiciones de servidumbre. Si bien el esfuerzo normativo fue encomiable (se establecieron ordenanzas en $1528,1535,1542,1545$ y 1547) existieron ciertos aspectos que quedaron al margen de las leyes, algo que pretendió subsanarse, de manera general para todos los territorios americanos, con la Recopilación de las Leyes de los Reinos de Indias en 1680. En la misma se reafirmaron los decretos legales desde comienzos de la colonización, confirmándose el uso de las provisiones de origen castellano como fuente de derecho supletorio, al ordenarse que en toda materia no cubierta por las disposiciones se guardasen las leyes de los reinos de Castilla ${ }^{9}$. Sin embargo, el complejo escenario que estableció la sociedad dominicana incidió en que

\footnotetext{
${ }^{4}$ Knight, 2007.

5 Blackburn, 1997.

6 De la Fuente, 2004: 383-387.

7 Laviña, 1991: 11-15.

8 Fergus, 2008: 75-99.

9 Altieri, 2009: 96.
} 
durante buena parte del largo tiempo colonial no se establecieran grandes regulaciones legales en materia de esclavos, por lo que fue la casuística la que fue recomponiendo el ordenamiento jurídico y sobre todo, la forma en la que podían ser interpretadas las leyes ${ }^{10}$.

El ordenamiento jurídico castellano habilitaba instituciones judiciales donde los esclavos podían acudir para denunciar los excesos de sus propietarios, entendiéndose como exceso el incumplimiento de las responsabilidades que éste adquiría con la compra ${ }^{11}$. La articulación de un sistema judicial donde tuvieran cabida las reclamaciones de los esclavos era un arma de doble filo, ya que si bien permitía la discusión al interior del propio sistema de las arbitrariedades cometidas por los amos, al mismo tiempo lo legitimaba ${ }^{12}$. Claro que la existencia de estas instituciones no implicaba necesariamente su eficacia. Así, una de las principales propuestas que trataron de establecerse durante la confección del Código Negro Carolino fue la homogeneidad de las instituciones de justicia que debían tratar los litigios planteados por los esclavos. La figura del Síndico Procurador, considerado en el proyecto reformista como protector de los esclavos, debía velar por el cumplimiento de las responsabilidades adquiridas por el propietario con la compra. Esta figura pretendía subsanar la incapacidad procesal de los siervos para establecer sus demandas, ya que según las Leyes de Indias los encargados de oír las quejas de los esclavos eran los oidores o los alcaldes en la Audiencia a través del Procurador de Pobres ${ }^{13}$. Se pretendía establecer un mediador entre esclavos y jueces, con una función específica (las demandas planteadas por los esclavos, segregándose de esta manera a esclavos y pobres) y de carácter local, con un mayor grado de proximidad al potencial demandante, ya que dicha función estaba inserta en el interior del cabildo.

No fue casual que el intento por reformar las instituciones de justicia en los dominios ultramarinos de la Monarquía Hispánica coincidiera temporalmente con políticas que pretendieron desarrollar el esclavismo. Las Ordenanzas del Cabildo de Santo Domingo de 1768 fueron articuladas en el contexto de la creación de la Compañía Gaditana de Negros tres años antes, que preveía la llegada de un importante contingente de esclavos a La Española. Lucena considera estas Ordenanzas como una gran recopilación de la tradición legal española y francesa sobre el tratamiento de los esclavos, y se realizaron por la necesidad de sujeción de los esclavos por el motivo de «no haber leyes

\footnotetext{
10 Premo, 2011: 498.

11 De la Fuente, 2010: 154-173.

12 Stern, 1982.

13 Varella, 2011: 119.
} 
municipales que prescriban el modo de gobernar en esta isla los negros esclavos $\gg{ }^{14}$. Aunque como ya hemos señalado, existían normativas legales desde comienzos de la colonización, éstas se alejaban de los nuevos supuestos que observaba la Corona, al considerarlas incompatibles, por anacrónicas, con las nuevas formas de dominio que se pretendían implementar al calor del desarrollo de esclavismo y porque, en buena medida, su grado de cumplimiento distaba mucho de ser el deseado ${ }^{15}$.

En la redacción del Código negro carolino (elaborado en 1784 y difundido para todos dominios españoles en América a través de la Real Cédula de 31 de mayo de 1789) se retomaron los aspectos fundamentales señalados en las ordenanzas de 1768. En su elaboración quedaron claras las diferencias de criterio entre la Gobernación y la Audiencia de Santo Domingo, ya que ambas instituciones pretendieron abrogarse un papel protagónico en los asuntos referidos al tratamiento de los esclavos, y su promulgación generó un profundo malestar ${ }^{16}$. Estaba dirigido a los propietarios, para que éstos actuaran en la forma que las autoridades establecieron como más justas y favorecedoras para el desarrollo económico y la seguridad del territorio ${ }^{17}$. Para D. Joaquín García, la necesidad de arbitrar un nuevo marco legal residía en la gran cantidad de esclavos que habitaban los campos sin sujeción de sus amos, siendo un continuo problema para el bien público, tanto por la escasa productividad de sus cultivos como por haberse convertido en protectores de cimarrones ${ }^{18}$. El daño que el interés público sufría por un inadecuado uso del dominio explicaba la interposición de las autoridades políticas de la colonia en materia tan reservada y privada como el trato de los esclavos. En opinión de las autoridades, era necesario captar toda la fuerza laboral disponible, que se encontraba dispersa por los campos dominicanos, para lograr el desarrollo del sector azucarero. Pero además, como señala Buscaglia, el código negro pretendía desarrollar un ordenamiento racialista de la esclavitud, al marcar las posibilidades de obtención de la libertad, y la orientación laboral, en base al color del esclavo. Éste debía ser negro y trabajar en los cañaverales que, imaginaban las mentes ilustradas, se extenderían como un reguero de pólvora hasta la

\footnotetext{
14 Lucena Salmoral, 2000: 296.

15 Moreta Castillo, 2008: 31-48.

16 Carta del Gobernador D. Isidro de Rojas Peralta, Santo Domingo, 25 de marzo de 1785, Archivo General de Indias, Sevilla (AGI), Santo Domingo, 947.

17 Malagón Barceló, 1974.

18 Carta de D Joaquín García, Teniente del Rey, a los presidentes y decano de la Real Audiencia de Santo Domingo, sobre la redacción de un código de leyes y ordenanzas para el gobierno económico, político y moral de los negros de esta isla, Santo Domingo, 14 de marzo de 1784, AGI, Santo Domingo, 946-B.
} 
frontera del Saint Domingue al calor de las políticas reformistas. Además, éste esclavo negro contaría con escasas o nulas posibilidades de obtener la libertad, mientras que, de manera contemporánea, se canalizaban las aspiraciones de obtener la manumisión de los esclavos mulatos, al orientarlos profesionalmente a rubros económicos donde pudieran estar en contacto directo con circuitos económicos donde pudieran obtener la capitalización necesaria para satisfacer el precio de coartación. Además se facilitaba, por la vía matrimonial, el blanqueamiento de éste sector poblacional ${ }^{19}$. El código negro carolino negaba la posibilidad de dedicar a profesiones mecánicas, de alta especialización, a «ningún negro o pardo tercerón», quedando reservados estos oficios a «las personas blancas, cuarterones o mestizos, por preferencia a su color ${ }^{20}$. Esta medida se vio acompañada por otras, como la Real Cédula de 28 de febrero de 1789, que liberalizaba el comercio de esclavos para buena parte de los puertos del Caribe, que en su artículo 8 expresaba que los propietarios que no tuviesen a sus esclavos dedicados a tareas agrícolas debían pagar un impuesto anual per cápita de dos pesos. Esta disposición provocó cierto revuelo en Santo Domingo, cuyo gobernador expresó el descontento que su aplicación podía acarrear en la colonia, proponiendo eximir de la capitación a los esclavos domésticos y sugiriendo que no tuviera un efecto retroactivo ${ }^{21}$.

A los estímulos fiscales había que añadir, además, la revitalización de las instituciones políticas de carácter local, que debían vigilar que los propietarios ejercieran de manera correcta el dominio que tenían conferido, o al menos, interpretarlo en la manera que las autoridades consideraban como más beneficiosa para el bien común. Este conjunto de acciones suponían una interferencia por parte de la Monarquía en las particulares relaciones que establecían los amos con sus esclavos, convirtiéndose en un obstáculo insalvable e intolerable que provocó el rechazo frontal de la clase propietaria, dejando en suspenso su aplicación en una coyuntura marcada por la inestabilidad de Saint Domingue 22 . Los propietarios observaban el nuevo código con actitud negativa, determinada por la pérdida de poder y autoridad que podían detentar frente a sus esclavos por injerencias externas.

La distancia entre los nuevos marcos legales y las prácticas esclavistas previamente establecidas quedaron patentes en Santo Domingo, provocando

19 Buscaglia, 2014 (consultado gracias a la amabilidad del autor).

20 Malagón Barceló, 1974: 184.

${ }^{21}$ El Gobernador de Santo Domingo participa testimonio y pide decisión sobre los puntos cuestionables de la cédula sobre la franquicia y capitación de los negros, Santo Domingo, 25 de febrero de 1790, AGI, Santo Domingo, 953.

${ }^{22}$ Lucena Salmoral, 1996: 7. 
grandes contrastes entre lo posible y lo realizable, entre las leyes y su seguimiento, e incluso, como en el caso que nos ocupa, la propia vigencia de nuevas normativas legales. La coincidencia de estas protestas generalizadas en los dominios hispánicos de América con el estallido revolucionario en la colonia del Saint Domingue, postergó su implementación sine die. Sin embargo, la percepción de que las instituciones políticas debían actuar en materia de esclavitud siguió estando presente. En el año 1795, desde la Audiencia de Santo Domingo, y ante el estruendo que el proceso revolucionario del Saint Domingue estaba generando por la abolición de la esclavitud por parte de la República (jacobina) Francesa, se articuló un nuevo proyecto reformista. Si los anteriores pretendieron establecer un marco favorecedor para el desarrollo del esclavismo, en ésta ocasión el objetivo se antojaba bien distinto. D. José Antonio Urízar, miembro del Consejo de Indias y Regente de la Audiencia de Santo Domingo, escribió un discurso sobre la modificación y límites de la esclavitud en el que se pretendía establecer una normativa fija y uniforme por la que los esclavos pudieran recibir la libertad como premio. En él, se argumentaba que al igual que sucedía en diferentes rubros profesionales como el ejército, la administración o el clero, donde el celo y el leal servicio se veía recompensados con ascensos y honores, en materia de esclavitud debía seguirse el mismo principio. En su opinión, los esclavos que hubieran prestado un servicio leal por veinticinco años, y a los que no se les pudiera tachar de criminales o irrespetuosos con la religión, debían adquirir, si así lo solicitaban, la libertad. De esta manera, se pretendía establecer un escenario real, un umbral cierto, en el que el esclavo podía obtener la libertad si se ajustaba a los designios de su propietario ${ }^{23}$. Además, se pretendía desactivar el incentivo que la insurgencia jacobina podía significar para los esclavos de los dominios españoles, que podían verse alentados a la rebelión en pos de la consecución de la libertad. El discurso no tuvo mayor trascendencia pero, en cualquier caso, ponía sobre la mesa la voluntad política de las autoridades por normativizar la esclavitud en el mundo hispánico en función de la coyuntura vigente, ya fuera para desarrollar modelos de plantación, ya fuera por la mera preservación de la institución.

La necesidad de establecer un marco legal unitario para regular el mundo de la esclavitud provenía tanto de la multiplicidad de ordenanzas municipales como de las costumbres y normas que se habían habilitado en suelo dominicano durante buena parte de la colonización y que caracterizaban las relacio-

23 Discurso sobre modificación y límites de la esclavitud, formado por D. José Antonio de Urizar del Supremo Consejo de Indias, y actual Regente de la Real Audiencia de Santo Domingo, Santo Domingo, 25 de junio de 1795, AGI, Santo Domingo, 958. 
nes amo-esclavo. El desarrollo de los modelos de plantación y el consecuente auge del esclavismo reclamaban, en opinión de las instituciones políticas, del establecimiento de unas normas fijas que regulasen todos los aspectos de la vida del esclavo, depositando la responsabilidad, si esto no sucedía, en su propietario. Estos proyectos de «gobierno del desgobierno», nos invitan a repensar en las dinámicas de la esclavitud dominicana, alejada de los grandes modelos de plantación, que tuvo unas características bien definidas, claramente observables en el estudio de la documentación jurídica.

\section{LAS DIFERENTES CARAS DEL DOMINIO}

La propiedad de un esclavo podía obtenerse de varias maneras. La herencia, la compra, la donación o la permuta fueron los instrumentos utilizados por los propietarios para justificar el dominio que ejercían sobre sus esclavos. Esta serie de acciones, que han sido registradas en diferentes repositorios documentales como contratos de compraventa, litigios judiciales o disposiciones testamentarias, nos muestran una serie de prácticas sociales realizadas por propietarios y esclavos para, bien obtener o consolidar su dominio frente a los esclavos o a otros propietarios, bien conseguir ciertos márgenes de libertad que distorsionaban el dominio de sus propietarios.

Los contratos de compraventa nos ofrecen una rica información sobre las formas de pago, el crédito o las diferentes motivaciones que impulsaron, tanto a compradores como a vendedores, a realizar la transacción económica. Por lo general, las transacciones se realizaban en metálico, casi siempre en moneda de plata, si bien, durante el periodo de ocupación francesa algunas se realizaron en moneda de oro $^{24}$. El esclavo no era una mercancía barata, por lo que su compra suponía un fuerte desembolso económico. Por ello, en ocasiones una parte del pago se realizaba en efectivo y la otra en moneda circulante de bajo valor ${ }^{25}$, o bien en frutos del país ${ }^{26}$. Incluso, en alguna ocasión,

24 Contrato de compraventa de la esclava mulata Eudovigia, El Seibo, día y mes ilegible, 1808, Archivo General de la Nación Santo Domingo (en adelante AGN), Fondo del Archivo Real de El Seibo (en adelante ARS), leg. 32.

25 Contrato de compraventa de la esclava Vicenta entre $D^{a}$ Josepha Miniel y D. Antonio Pambrón, Santo Domingo, 16 de julio de 1817, AGN, Protocolos Notariales, dep. 7 IT 09277 , José Troncoso, 1812. La cantidad pagada por la compra de la esclava fue de 110 pesos fuertes efectivo y 80 en cobre, a razón de cuatro y medio por uno.

${ }_{26}$ Contrato de compraventa del esclavo Alejandro entre Gabriel Durán e Isabel María de Castro, El Seibo, 11 de junio de 1819, AGN, ARS, leg. 46. 
si el vendedor observaba que era una buena ocasión para obtener por medio de la transacción un producto de alto valor, ésta se realizaba ${ }^{27}$. En otras ocasiones, los valores de los esclavos, o de las deudas contraídas con anterioridad por el comprador o el vendedor afectaban el transcurso de la transacción ${ }^{28}$. La circulación monetaria no está constituida por la cantidad de monedas acuñadas, sino por las que circulan realmente, y sobre todo que estén a disposición de todos los agentes económicos. Para el caso antillano, a pesar del incremento de las remisiones de plata mexicana que se registraron en la segunda mitad del siglo XVIII, esta salió con relativa rapidez de territorios como Cuba o Santo Domingo, dado el incremento de la actividad comercial y la presencia cada vez más frecuente de comerciantes extranjeros ${ }^{29}$. Esto es, que en ocasiones, dadas las dificultades existentes para que los actores económicos dispusieran de moneda, éstos optaban por utilizar en parte de sus transacciones otros bienes que, puestos en valor, pudieran ser aceptados como «moneda» de cambio ${ }^{30}$. La moneda servía, en muchas ocasiones como medida de valor, no utilizándose necesariamente en la totalidad de las transacciones económicas que se daban en la colonia ${ }^{31}$. De hecho, esta monetarización de los bienes también afectaba a los esclavos que, como cualquier otra propiedad privada, eran tasados en base a su precio de mercado y su valor monetario podía ser utilizado, total o parcialmente, para pagar servicios, avalar negocios o incluso saldar las deudas de su propietario a través del embargo ${ }^{32}$. Si bien en la mayor parte de las ocasiones los registros documentales señalan que las transacciones se realizaron al contado, no fue infrecuente que los compradores recurrieran al crédito ${ }^{33}$. El plazo en el que debía pagarse el esclavo comprado era varia-

27 Contrato de compraventa de la esclava María Asunción por parte de D. Juan Cleresó y D. Cristóbal de Aponte, El Seibo, 3 de octubre de 1764, AGN, ARS.

28 Contrato de compraventa de la esclava Juliana entre el Capitán D. Santiago Lama y D. Francisco Martín, Santo Domingo, 8 de marzo de 1818, AGN, Protocolos Notariales de José Troncoso, leg. 13710.

29 Romano, 1998: 40-57.

30 Contrato de compraventa del esclavo Antonio celebrado entre D. Juan Rodríguez y D. Manuel Martín, Capitán de milicias. Bayaguana, día y mes ilegible, 1813, AGN, Archivo Real de Bayaguana (en adelante ARB), leg. 30. El pago se realiza por « 230 pesos que confieso haber recibido en otros tantos barriles de melado».

31 Silié, 2009.

32 Demanda de D. Miguel Flebes contra los bienes de Miguel García, El Seibo, 28 de junio de 1807, AGN, ARS, leg. 32.

33 Contrato de compraventa de siete esclavos bozales entre D. Pedro Parreño, Capitán de la fragata española La Prudencia de Cádiz, y D. José Díaz, vecino de Azua, Santo Domingo, 20 de junio de 1818, AGN, Protocolos Notariales de José Troncoso, Libro 13710. 
ble ${ }^{34}$, y era fijado por comprador y vendedor, bien en el momento de la compra, bien en un contrato particular aparte, en el que se podía incluir la opción de una subida de precio del esclavo por haberse utilizado esta forma de pago ${ }^{35}$.

Por lo general, las condiciones que se explicitaban en los contratos de compraventa respondían a las necesidades de los firmantes, que pretendían salvaguardar, por encima de todo, sus intereses particulares. Si bien la apropiación de la capacidad de trabajo del esclavo fue el estímulo mayoritario para que se efectuaran las compraventas, también existieron otro tipo de motivaciones. La más frecuente fue la liquidación de deudas contraídas bien por el vendedor, bien por un familiar cercano ${ }^{36}$. En otras ocasiones, la compraventa se producía en el momento de la muerte del propietario, y el objeto de la misma estaba determinado por la satisfacción de los herederos, para asegurar, en la medida de lo posible, sus perspectivas económicas, especialmente si los mismos eran menores ${ }^{37}$.

Para algunos esclavos fue posible mediatizar o impulsar la compraventa, si bien esta posibilidad estaba condicionada por la capacidad de presión del esclavo y el grado de dependencia que el propietario tuviera del mismo ${ }^{38}$. Si se daban las circunstancias oportunas, si la capacidad de presión que ejercía el esclavo, de manera directa o indirecta, tenía efectos sobre el dominio de su propietario, la solicitud de cambiar de amo no era una quimera, especialmente si se ofrecían condiciones ventajosas para realizar la variación de dominio. La propia redacción del código negro carolino establecía que la capacidad para cambiar de amo era un alivio necesario para los siervos, siempre que éstos hubieran experimentado un domino cruel que hubiera puesto en riesgo su vida. Sin embargo, también señalaba que las variaciones de domino no podían llevarse a cabo por el mero capricho de los esclavos, o por el temor a un castigo fundamentado, ya que de lo contrario se pondría el riesgo el derecho de propiedad, por lo que se establecía que para que se llevaran a cabo,

34 Contrato de compraventa del esclavo Andrés celebrado entre D. Blas Fernández de Castro y Madama María Reyna Bocier, El Seibo, 2 de agosto de 1819, AGN, ARS, leg. 46.

35 Contrato de compraventa de la esclava María Merced celebrado entre D. Antonio López y D. Pedro Nolasco Berroa, El Seibo, 5 de julio de 1806, AGN, ARS, leg.46.

36 Contrato de compraventa celebrado entre el Presbitero D. José Antonio Lemos y Ramón Alonso por el esclavo Ramón, El Seibo, 2 de octubre de 1818, AGN, ARS, leg. 36.

37 Contrato de compraventa celebrado por Alejandro de Mota y D. Manuel Peguero por el esclavo Dionisio, El Seibo, 27 de enero de 1819, AGN. ARS, leg. 46.

38 Contrato de compraventa de la esclava María de la Ascensión, criolla como de 30 años, celebrado entre Alejo Sánchez e Hilario Lorenzo, El Seibo, 17 de agosto de 1818, AGN, ARS, leg. 36. 
debían estar absolutamente justificadas ${ }^{39}$.Esta medida pretendía imposibilitar la capacidad de presión que algunos esclavos podían ejercitar contra sus amos. $\mathrm{Y}$ es que en ocasiones, los esclavos buscaban un nuevo amo sin la licencia oportuna, lo que provocaba serios conflictos, dirimidos con frecuencia, en los tribunales de justicia ${ }^{40}$.

Las acciones de resistencia de los esclavos podían hacer que el dominio de sus propietarios resultara inaplicable, impulsando de esta forma su venta. En este sentido, D ${ }^{\mathrm{a}}$ Josefa Acosta, vecina de Santo Domingo, abrió diligencias para solicitar la enajenación del dominio que tenía sobre un esclavo denominado Felipe, propiedad de sus hijos menores, por «la mala índole y tachas de fugador y cimarrón» habilitándose a ésta para «que pueda venderlo con expresión de las tachas y su sedisoría» ${ }^{41}$. Un dominio imposible de ejercer, generado gracias al conflicto planteado por el esclavo, era, para propietarios con escasa capacidad para imponer su voluntad, un grave problema, por lo que la venta era una opción atractiva de la que además, podía obtener una compensación económica. Sin embargo, las autoridades pretendían eliminar esta práctica, ya que en la redacción del código negro carolino se explicitaba que si la compraventa se establecía gracias a las «malas artes» del esclavo, se debía recargar significativamente tanto el precio de su venta como el derecho de alcabala que debía pagarse en la transacción ${ }^{42}$. La desafección que los amos podían profesar a sus esclavos podía condicionar los contratos de compraventa, en los que se exponían cláusulas que trataban de evitar cualquier posibilidad de devolución. Así, Valeriana Ruiz vendió a $D^{a}$ Rosenda Mercedes una esclava mulata, llamada María, criolla, de 20 años, a la que vendió «con todas las tachas, públicas y secretas» con la expresa condición de que «por uno u otro motivo me la pueda devolver ${ }^{43} \gg . \mathrm{D}^{\mathrm{a}}$ Rosenda Mercedes fue algo más explícita al vender a $\mathrm{D}^{\mathrm{a}}$ María de Quesada una esclava criolla, llamada Antonia, de 37 años, «lastimada de las caderas según ella dice (...) sin más

39 Malagón Barceló, 1974: 206-207.

40 Pleito de Sebastián Álvarez, Sargento de la compañia de milicias de El Seibo, contra Baltasar Guerrero, El Seibo, 22 de enero de 1773, AGN, ARS, leg. 47. El origen del pleito radicaba en la petición del primero de la anulación de la compraventa efectuada por una esclava mulata llamada Elena, ya que entre sus tachas no se especificaba que «a más de dos veces, la citada esclava se le había ido al Seibo en busca de amo».

${ }^{41}$ Diligencias emprendidas por María Josefa de Acosta, Santo Domingo, 15 de diciembre de 1821, AGN, Comprobantes de protocolos notariales de Andrés Julio Montelio, leg. 40.

42 Malagón Barceló, 1974: 207.

43 Contrato de compraventa de la mulata María celebrado entre Valeriana Ruiz y $D^{a} R o-$ senda Mercedes, El Seibo, día y mes ilegible, 1807, AGN, ARS, leg. 32. 
tacha que la de ser sumamente perra y soberbia de genio con la expresa condición de que no se la pudiera devolver»44.

Tal vez, la coartación fue el instrumento que, utilizado por el esclavo, condicionó con mayor frecuencia los procesos de compraventa. La coartación era el derecho legal, adquirido de manera consuetudinaria, por el que el esclavo podía comprar a plazos su libertad, pagando a su dueño diferentes cantidades de manera periódica que se iban anotando en su título de compra y que abarataban el precio del esclavo, ya que debían reconocerse las entregas de capital entregadas que debían ser restadas a su precio de mercado ${ }^{45}$. Este proceso requería de un principio de confianza, si bien los esclavos debían reclamar recibos que justificasen las entregas realizadas al amo para evitar posibles abusos. El precio de la libertad debía ser acordado entre amo y esclavo, si bien, se podían producir alteraciones en los términos del acuerdo, cambiándose, y en ocasiones, revocándose ${ }^{46}$. Francisco del Rosario, esclavo de Antonio de Guzmán, interpuso un juicio a su propietario, ya que pretendió libertarse por una cantidad menor a la establecida por encontrarse quebrado. Ante la negativa del propietario de rebajar el precio de coartación pedido por el esclavo, éste recurrió a los tribunales de justicia para que se nombrasen tasadores que, atendiendo a sus enfermedades y teniendo en cuenta que ya había entregado 70 pesos en beneficio de su libertad, establecieran un precio justo de corte ${ }^{47}$. El precio de coartación fluctuaba en función del valor de mercado del esclavo. Por ello, cuando las condiciones del esclavo cambiaban, incrementando o disminuyendo su valor, el precio de coartación debía ajustarse a ésta realidad, si bien en ocasiones, cuando los esclavos accedían finalmente a la libertad, debían pagar más de lo estipulado a sus propietarios, como incentivo para adquirir la libertad ${ }^{48}$. Para los redactores del código negro, ésta práctica era vista con malos ojos, ya que producía un fraude de ley que debía ser eliminado, lo que suponía un perjuicio claro para los propietarios y una clara limitación de dominio de éstos que condicionaba su capacidad para otorgar la libertad ${ }^{49}$. Pero además, la coartación era interpretada como un foco de potenciales problemas de orden público, ya que los propietarios no

44 Contrato de compraventa de la esclava Antonia celebrado entre $D^{a}$ Rosenda Mercedes y $D^{a}$ María de Quesada, El Seibo, día y mes ilegible, 1807, AGN, ARS, leg. 32.

45 Lucena Salmoral, 1999: 359.

46 Codicilo del testamento de Pedro Hermoso, Santo Domingo, día y mes ilegible, 1812, AGN, Protocolos Notariales de José Troncoso, 1812.

47 Reclamación del esclavo Francisco del Rosario, Santo Domingo, día y mes ilegible, 1758, AGN, ARS, leg. 29.

48 Kemner, 2010.

49 Malagón Barceló, 1974: 208. 
vigilaban la procedencia del dinero que les era entregado y no se preocupaban de que el esclavo hubiera adquirido buenas costumbres. Como se señala en el capítulo 19, ley sexta del código, se prohibía a los esclavos coartados que realizaran entregas de dinero que excediesen la mitad o las dos terceras partes de su valor, ya que no era extraño que algunos decidieran pagar la práctica totalidad de su precio sin satisfacerlo totalmente, lo que les permitía vivir de manera ociosa, trabajando por un escaso jornal, y sin tener la voluntad de pagar el resto del precio, evitando así las responsabilidades tributarias o militares de la población libre ${ }^{50}$.

\section{DisCUTIENDO EL DOMINIO}

El dominio que ejercía el propietario sobre el esclavo no era uniforme, sino que frecuentemente estaba sometido a diferentes variables que en ocasiones distorsionaban su capacidad para extraer la mayor cantidad posible de trabajo del esclavo o establecer con firmeza su voluntad. En buena medida, la relación amo-esclavo estuvo determinada por un proceso de negociación, nunca entre iguales, en un entorno expuesto a cambios, que si bien no discutía la consideración jurídica de los sujetos esclavizados, si podía afectar a las condiciones del dominio al que estaban sometidos ${ }^{51}$. En este juego de relaciones se establecían las normas básicas de dominio, la orientación laboral del esclavo o sus condiciones de vida, por lo que el proceso no estuvo exento de tensiones y, en ocasiones, de violencia.

Los propietarios eran renuentes a acudir a instituciones de justicia cuando un esclavo de su propiedad transgredía sus disposiciones. Además de ser considerado como algo privativo del dominio que ejercía, acudir los tribunales implicaba que debía realizar una enajenación de dominio temporal del esclavo para que la justicia actuase, además de estar obligado a pagar las costas procesales y la manutención del esclavo durante el tiempo que estuviese en la cárcel. Sin embargo, en ocasiones, se vieron obligados a recurrir a ellas. Ramón Henríquez, vecino de Higüey, demandó ante las autoridades de justicia a un esclavo de su propiedad, llamado Regino, "por haber tenido éste la osadía y atrevimiento de atropellarle, injuriarle y amenazarle gravemente» ${ }^{52}$. El esclavo fue sentenciado a cincuenta fuetazos, que debían aplicarse

\footnotetext{
50 Ibidem: 203.

51 Gudmunson, 2003: 110.

52 Pleito de Ramón Henríquez contra un mulato su esclavo nombrado Regino, Higüey, 13 de abril de 1810, AGN, ARH, leg. 26.
} 
de manera pública, si bien el propietario reclamó aplicarla él mismo en la privacidad de su casa, tal vez en un intento por preservar la autoridad que pretendía mantener sobre su siervo.

Otro de los factores que marcaban una interrupción del dominio era la muerte del propietario, al menos mientras que a los herederos no les fuera reconocida la propiedad. Por tanto, el testador debía exponer con absoluta claridad el inventario y valor de los bienes para evitar conflictos con los beneficiarios, así como el destino final de los $\operatorname{mismos}^{53}$. Sin embargo, a pesar de las disposiciones que hubiera podido establecer el propietario difunto, en ocasiones los herederos pretendían desconocer ciertas cláusulas de los testamentos que rebajaban el precio de coartación u otorgaban la libertad a escla$\operatorname{vos}^{54}$. Estas acciones de los herederos eran frecuentes cuando las disposiciones testamentarias otorgaban condiciones de dominio ventajosas para el esclavo. En el testamento de Juana de San Pedro se señalaba que tenía «una mulatita llamada Petrona que es mi voluntad no pueda ser avaluada ni vendida en ningún tiempo en más de 175 pesos, porque aunque conozco que vale mucho más de ello, le hago gracia y donación por haberme sido leal y acompañado en todas mis enfermedades y trabajos, encarando que si fuera su voluntad, le sirva a mi hijo Lorenzo para que me lo cuide, y en caso de querer ella, mando se le agregue a la parte de mi dicho hijo Lorenzo ${ }^{55}$. Además de la rebaja del precio de coartación, la difunta propietaria otorgaba la capacidad de elegir dueño a su esclava, que sería, en última instancia, la que decidiera su futuro propietario.

Ante cláusulas de este tipo, los herederos reaccionaban tratando de implementar un dominio más severo, por lo que era de capital importancia para los esclavos obtener la documentación acreditativa de su condición, ya que les protegía contra posibles y futuras acciones de los propietarios, ofreciendo una mínima garantía jurídica que les habilitaba a acudir a los tribunales de justicia $^{56}$. Esta confrontación entre testadores y herederos no pasó por alto para las autoridades coloniales. D. Joaquín García señalaba que el escaso interés en preservar el patrimonio que constituían los esclavos para los herederos, era un grave problema, tanto de índole privado como público, ya que generaba

53 Tasación de bienes de Francisca Cueto, El Seibo, 23 de diciembre de 1818, AGN, ARS, leg. 28.

54 Testamento de D. Joseph Rodrígues, El Seibo, 1 de diciembre de 1804, AGN, ARS, leg. 40 .

55 Testamento de Juana de San Pedro Herrera, El Guasumal, 8 de febrero de 1773, AGN, ARS, leg. 40.

56 Real Provisión ejecutoria en la que se da por libre a Paula María de la Rosa y sus hijos, Santo Domingo, día y mes ilegible, 1722. AGN, ARS, leg. 29. 
en los esclavos agraciados por este tipo de medidas poco incentivo para continuar con los trabajos que les asignaban sus amos, con el consecuente agravio para el interés común ${ }^{57}$. Las fuentes nos sugieren que estos procedimientos fueron más frecuentes entre los pequeños propietarios de esclavos. Dado el grado de dependencia que tenían éstos del trabajo de sus esclavos, eran más renuentes a otorgarles este tipo de beneficios en vida; sin embargo con objeto de garantizar su fidelidad, los propietarios ofrecían un escenario futuro, hipotético, pero alcanzable, en el que a su muerte sí podrían materializarse todos los beneficios que, a modo de incentivo, les ofrecían, lo que no necesariamente iba en beneficio de los herederos ${ }^{58}$.

Los intentos de re-esclavización no quedaron constreñidos, exclusivamente, al desconocimiento de cláusulas testamentarias. En buena medida porque no era extraño que los acuerdos legales no se formalizara por escrito y, sobre todo, porque la re-esclavización era una buena opción para adquirir la mano de obra que requerían, tuviera o no el esclavo el resguardo legal suficiente ${ }^{59}$. En un escenario complejo de relaciones, los propietarios tendían a incumplir los acuerdos a los que habían llegado con sus esclavos para la consecución de la libertad, por lo que éstos debían defender su nuevo status jurídico en los tribunales de justicia. Para ello, requerían conocer tanto los procedimientos relativos a la salvaguarda de sus derechos, como conservar la documentación que avalaba su status de hombres y mujeres libres, en un proceso análogo al estudiado por Alejandro de la Fuente para el siglo XIX cubano ${ }^{60}$. Este tipo de estrategias estuvieron vigentes incluso a lo largo del gobierno de Ferrand (1804-1809), quien pretendió establecer una normativa inspirada en el Código Negro francés que endurecía las condiciones de servidumbre ${ }^{61}$.

Ferrand desconoció por completo los decretos de abolición de la esclavitud aplicados por el República Francesa en 1794, por lo que, todos aquellos es-

57 Carta de D Joaquín García, Teniente del Rey, a los presidentes y decano de la Real Audiencia de Santo Domingo, sobre la redacción de un código de leyes y ordenanzas para el gobierno económico, político y moral de los negros de esta isla, Santo Domingo, 14 de marzo de 1784, AGI, Santo Domingo, 946-B

58 Freire, 2011: 211-232. En este trabajo, Freire señala la necesidad de poner en relación las diferentes fuentes jurídicas en las que se recoge el acceso a la libertad de los esclavos, como cartas de libertad, documentos bautismales o testamentos, ya que nos puede ofrecer una visión más rica a la hora de entender los procesos por los cuales los esclavos obtenían la libertad, así como las estrategias seguidas por los propietarios.

59 Reclamación de esclavo, Santo Domingo, día ilegible, marzo 1815, AGN, Comprobantes de protocolos notariales de Andrés Julio Montelio, leg.40.

60 De la Fuente, 2007: 659-692.

61 Nessler, 2012: 16. 
clavos que, procedentes del Saint Domingue y radicados en Santo Domingo, hubieran quedado liberados por los decretos jacobinos, debían caer de nuevo bajo servidumbre. Esta medida provocó un gran impacto en el territorio dominicano, por lo que Ferrand optó por establecer diferentes canales para tratar de regularizar la situación. Aquellos que pudieran demostrar su condición de libres, o adquirir dicho status, quedarían al margen de la re-esclavización. Para ello, se estipularon tres vías a la que podían acudir los re-esclavizados para cambiar su situación, que eran la compra de la carta de libertad en un precio establecido de antemano acorde con su valor de mercado, la llamada de testigos que pudieran confirmar que habían sido liberados, y por último, mostrar documentación acreditativa de su liberación, algo que en ocasiones resultaba complicado por la destrucción sistemática de buena parte de la documentación de la colonia francesa durante el proceso revolucionario. La reacción de las potencias esclavistas ante los decretos de abolición jacobinos fue perceptible para muchos ex-esclavos, quienes establecieron estrategias individuales para alcanzar la libertad eludiendo las disposiciones ratificadas por las autoridades metropolitanas francesas cuando acudían a otras colonias $^{62}$.

La pretensión, por parte de los propietarios dominicanos, de captar la mayor cantidad de mano de obra esclava posible, también afectó a otros amos. En opinión de Rudolf Widmer, existió en el siglo XVIII dominicano una clara competencia por parte de la clase propietaria de esclavos, en especial de los hateros, por captar siervos ajenos ${ }^{63}$. Probablemente, la estrechez del mercado de esclavos imposibilitaba, o al menos dificultaba, la capacidad de compra o reposición de mano de obra esclava, por lo que los propietarios pugnaban por atraer bajo su dominio a esclavos potencialmente rentables. Para evitar este tipo de estrategias, los propietarios debían legitimar el dominio sobre sus propios esclavos para evitar usurpaciones, a pesar de lo cual, en ocasiones, la redacción escrita de la compraventa se demoraba años, siempre en base a la petición del comprador ${ }^{64}$. Y en ocasiones esta legitimación documental nunca se formalizaba, como ha quedado patente en múltiples testa-

\footnotetext{
62 Scott, 2011: 1070.

63 Widmer, 2004: 161.

${ }^{64}$ Contrato de compraventa del esclavo Simón celebrado por Manuel Mauricio y Agustín Alemán, El Seibo, 22 de noviembre de 1794, AGN, ARS, leg. 49: «Habiendo vendido un negro mi esclavo llamado Simón a Agustín Alemán, también vecino, habrá tiempo de tres años, y no haberle hecho la correspondiente escritura, habiéndolo el dicho comprador reclamado para su resguardo ...».
} 
mentos en los que el testador avisaba a sus herederos de que parte o la totalidad de una transacción de esclavos aún quedaba pendiente ${ }^{65}$.

Los tribunales de justicia se convirtieron en el último escenario donde los propietarios dirimieron sus diferencias en torno a la propiedad de un esclavo. Salomé Díaz, vecina de Higüey, reclamó 250 pesos a Josepha Díaz por haber utilizado un negro esclavo de su propiedad, abrogándoselo como propio. La Justicia estableció el nombramiento de «dos hombres buenos, uno por cada parte» para que resolviese a quién pertenecía el esclavo. El dictamen judicial estableció que pertenecía a Salomé Díaz, lo que aseguraron tres testigos jurados (ninguna de las partes pudo certificar la propiedad con documentación), condenándose a Josepha Díaz al pago de una cantidad en calidad de compensación $^{66}$. La usurpación del dominio era pues, una realidad en el complicado escenario dominicano, en el que la búsqueda de la posesión de esclavos, y de los réditos que ofrecía su trabajo, fue una constante. Debemos distinguir, no obstante, que los esclavos que eran demandados, y por tanto, susceptibles de ser captados, eran aquellos de los que se presumía se podía obtener buenos réditos gracias a su capacidad de trabajo.

El proyecto carolino pretendió establecer de manera taxativa la imposibilidad de los propietarios de vender, por separado, a los miembros de una misma familia ${ }^{67}$. Se pretendía de ésta manera interferir en la capacidad de dominio de los propietarios, ya que no era extraño que se dieran éste tipo de actuaciones. El análisis de la documentación sugiere que, cuando el objeto de la compraventa era una esclava con hijos menores de un año, éstos últimos solían entrar dentro de la transacción, incrementando levemente el precio. Sin embargo, en ocasiones, estas estrategias, encaminadas probablemente a conseguir, de un lado, un mayor número de esclavos por parte del comprador a precio razonable y, de otro lado, preservar una línea familiar matrifocal que podía evitar algunas formas de resistencia de la esclava, no se cumplieron ${ }^{68}$. En otras ocasiones, simplemente una de las partes no estaba interesada en la compraventa del menor, pero sí de la madre. Pedro Martín Doroteo vendió a D. Manuel Fernándes una esclava de su propiedad llamada Juana Bautista, que tenía una hija de tres meses. El precio de venta de la esclava fue de 250 pesos, a pagar en seis meses, dejando bien claro el vendedor que la hija de la

65 Testamento de Ignacio de Frías, Gobernador reformado de estos llanos, Bayaguana, 8 de junio de 1775, AGN, ARS, leg. 15.

66 Pleito de Salomé Díaz, Higüey, 13 de mayo de 1814, AGN, ARS, leg. 26.

67 Malagón Barceló, 1974: 209.

68 Testamento de Francisca del Valle, Hato mayor de El Coca, fecha ilegible, AGN, ARS, leg. 40 . 
esclava no entraba en la compraventa, si bien la esclava debía «criar y alimentar por el tiempo de un año el que se contará desde la fecha de esta y al año se me ha de entregar la dicha negrita por no entrar en la venta de la madre ni en su precio ni alimentación que sobre la alimentación no estoy obligado ni me obligo a pagar cosa alguna que por esto doy a la esclava en precio y cuantía de 250 pesos $^{69} \gg$. Cuando los amos no respetaban la integridad de la familia esclava, basada en el nexo que establecía la madre con un hijo de corta edad, la responsabilidad financiera del menor correspondía a la madre, y no a los propietarios.

\section{UNA ZONA DE GRISES}

El reconocimiento de que el esclavo pudiera tener un peculio en la América colonial española marcaba una profunda contradicción con el marco legal, ya que si bien el esclavo no tenía personalidad jurídica para tener propiedades (en virtud de lo cual todo lo que poseyera el esclavo pertenecía a su amo), a través de la prácticas sociales se había establecido y admitido esta costumbre en buena parte de la América colonial española sin grandes problemas. De hecho, incluso en la redacción del código negro se lo catalogaba como «uno de los mayores estímulos para la fidelidad del siervo», debiendo ser entregado a esclavos de probada fidelidad y reconocida virtud, si bien se señalaba que el jornal debía ser reducido, ya que de lo contrario el esclavo dejaría de ser dependiente de su amo, «pues sólo pensará en sacudir el yugo que lo oprime $\gg^{70}$. Para algunos propietarios, con escasa capacidad para establecer dominio sobre sus esclavos, la coartación se convirtió en un elemento que, lejos de reforzar la relación de dominación, la reformulaba, adquiriendo, en ocasiones, apariencias distorsionadas.

El monto del peculio quedaba establecido en base al acuerdo que pudieran alcanzar amo y esclavo. Este podía adoptar diferentes formas, desde una parte proporcional de los jornales que pudiera conseguir el esclavo, a capital que podía ser invertido en pequeñas explotaciones. La extensión de la esclavitud de jornal en Santo Domingo llamó la atención de Sánchez Valverde, quien la consideraba uno de los principales males que evitaba el desarrollo de un proyecto esclavista de magnitud en la colonia. En buena medida, porque los esclavos jornaleros, en su opinión, «viven sin disciplina ni sujeción [...] se

69 Contrato de compraventa de la esclava Juana Bautista celebrado entre Pedro Martín Doroteo y D. Manuel Fernándes, El Seibo, 2 de octubre de 1755, AGN, ARS, leg. 38.

70 Malagón Barceló, 1974: 200. 
ocultan y protegen unos a otros y a los que se escapan de las haciendas. Los pocos que trabajan lo hacen sin método, y en ganando en una semana para satisfacer el jornal de dos, descansan la segunda. Fuera de lo que es más frecuente es trampear a sus amos la mitad de los jornales ganados». Si bien debemos destacar que Sánchez Valverde realiza su crítica desde la perspectiva un proyecto reformista, que pretendía establecer en la colonia un sistema esclavista semejante al que los franceses habían desarrollado en Saint Domingue, nos parece reseñable la percepción de la laxitud del dominio que podían aplicar los propietarios, probablemente, como insinúa más adelante en su obra, por la gran dependencia que muchos pequeños propietarios tenían de los mismos $^{71}$. Así parece corroborarlo la información recogida en la documentación testamentaria, en la que algunos amos reconocían deber cantidades significativas de plata a esclavos de su propiedad ${ }^{72}$.

La escasa sujeción de algunos esclavos rurales, estaba determinada, además, por las condiciones que requería el trabajo esclavo en las explotaciones agropecuarias ${ }^{73}$. Pedro Santana señalaba que «en virtud de que su hermana Petrona de Santana, esclava de Juana de San Pedro, con consentimiento de esta le dio ahora hará 6 o 7 años de 22 a 23 pesos con el fin de que los distribuyese en puercos de crianza, y con su cuidado y manejo se los aumentara para el fin de su libertad. Con este motivo, el otorgante así lo ha ejecutado y en su poder los conserva, y añadiendo al tiempo que los está manejando le ha prometido que en un año le dará 300 pesos para el beneficio de su libertad $\gg^{74}$. El testimonio nos parece de gran importancia, ya que además de sugerir una relación de tipo proto-capitalista entre ama y esclava, el mismo puede ser interpretado como una forma de resguardo legal, ya que la esclava no parecía tener, dada la naturaleza del acuerdo realizado, ningún documento que la avalara. Pero además, y coincidiendo con lo señalado por Rebecca Scott para el caso de Cuba, la documentación reseña la existencia de economías propias de los esclavos ${ }^{75}$.

La disposición estable de tierras, trabajadas esencialmente por unidades familiares esclavas, con una relativa autonomía en la gestión de las actividades, orientada, en buena medida, a la auto-subsistencia, establecieron las bases

\footnotetext{
71 Sánchez Valverde, 1785: 150-151.

72 Testamento de Francisco Morales, El Seibo, 6 de marzo de 1813, AGN, ARS, leg. 40: «A mi negro Manuel Benítez le debo noventa y tres pesos (...) que se le darán de mis bienes».

73 Zeuske, 2004: 128-143.

74 Reclamación de Pedro de Santana, El Seibo, 15 de noviembre de 1779, AGN, ARS, leg. 41.

75 Scott, 2000.
} 
para el proceso de campesinización del esclavo ${ }^{76}$. El desarrollo de las actividades campesinas suponía una alternativa a los sistemas de plantación, en las que los propietarios buscaban optimizar la fuerza de trabajo eludiendo los costos de manutención y de reposición ${ }^{77}$. El sector ganadero era de una importancia extraordinaria y ofrecía, gracias a la continua demanda procedente del Saint Domingue, importantes beneficios. En un contexto donde la utilización permanente de mano de obra asalariada generaba ciertas dificultades, el empleo de la mano de obra esclava permitía cubrir parte de las necesidades de carácter permanente de la explotación, aunque para ello, los esclavos estuvieran sometidos a un dominio laxo ${ }^{78}$. Ésta práctica establecida por los amos no era bien vista por las autoridades de la colonia, que la consideraban como no de los principales males a erradicar, o que al menos se realizase con una mayor sujeción por parte de los amos y de las autoridades, si se pretendía establecer un marco de seguridad mayor en los campos como paso previo a una explotación más rentable de los $\operatorname{mismos}^{79}$. En cualquier caso, la existencia de esclavos rurales orientados a explotaciones agroganaderas estuvo más que presente en el último periodo colonial dominicano.

Así, cuando se estaba realizando la tasación de bienes de Petrona Martín, los tasadores relataron que se presentó ante ellos uno de los esclavos de la difunta preguntando en cuanto estaba tasada su libertad y que al reseñar el precio, el esclavo lo satisfizo con «17 reses vacunas, cada una en 6 pesos, una yegua en 25 pesos y 25 pesos en plata ${ }^{80}$. Al margen de la importante disposición de bienes de la que hizo gala el esclavo, es reseñable que el peculio podía recibirlo, además de en monedas, en cualquier objeto que pudiera ser monetarizado. Todo bien que estuviera en poder del esclavo, algo inviable desde el punto de vista jurídico, en realidad era calificado como ahorro orientado a la libertad, ya que cualquier bien material era susceptible de ser tasado y puesto en valor monetario. La libertad, o el anhelo de la misma, a través de la figura del peculio, fue el subterfugio utilizado por los esclavos para obtener jornales por su trabajo o detentar bienes, lo que suponía una importante brecha a la institución jurídica de la esclavitud.

\footnotetext{
76 Cardoso, 1988: 49-57.

77 Mintz, Sidney y Handman-Xifaras, Marie-Élisabeth, 1972: 135-147.

78 Gelman, 1989: 52-53.

79 D. Pedro Catany, Oidor Decano de la Real Audiencia da informe de la comisión que le confió, Santo Domingo, 25 de mayo de 1793, AGI, Santo Domingo, 956.

80 Tasación de bienes de Petrona Martín, El Seibo, 11 de noviembre de 1791, AGN, ARS, leg. 24.
} 
La existencia de estas economías campesinas con mano de obra esclava estuvo sujeta a tensión, ya que si bien se fundamentaban en un pacto, este podía variar en base a las necesidades económicas de los propietarios ${ }^{81}$. Sánchez Valverde señalaba que los esclavos jornaleros solían disfrutar del arriendo de tierras por un espacio de dos años como máximo, al término de lo cual debían abandonarla y comenzar la explotación en otro lugar ${ }^{82}$. Aparentemente, esta realidad establecería una incompatibilidad con los presupuestos establecidos por Cardoso en cuanto a la disposición estable de tierras por parte de los esclavos como parte del proceso de campesinización. Sin embargo, desde nuestro punto de vista, debemos tener en cuenta la actividad económica principal de las economías esclavas a pequeña escala, en este caso el manejo de ganado, para establecer que, de hecho, esta rara vez se veía interrumpida a pesar de mudar de ubicación en periodos temporales cortos. En opinión de Barickman, en el área del Caribe las posibilidades de autogestión de la producción y distribución de las pequeñas explotaciones campesinas capitalizadas por esclavos eran de gran importancia, lo que favorecía la explotación independiente de los recursos que los esclavos tenían a su alcance, estableciendo ellos mismos, no los propietarios, tanto el tipo de producción como la comercialización ${ }^{83}$.

La importancia de este sector en la economía dominicana nos sugiere que, dado que los esclavos acudían con cierta frecuencia a vender parte de su producción a los mercados locales, las autoridades debieron emitir algún tipo de regulación legal para reglamentar dichas actividades. Así, en el Bando de Buen Gobierno dictado por el Sr. Mariscal de Campo D. Carlos de Urrutia el 23 de abril de 1815 en Santo Domingo, se prohibía que los esclavos pudieran bailar en los velorios delante del cadáver, reunirse en número importante en fiestas realizadas a puerta cerrada, que se les alquilara cuartos o casas para pernoctar y se hacía responsable a los propietarios que dedicaban a sus esclavos a «ganar jornal, vendiendo por las calles ropa, comestibles u otros géneros, de las trampas y malversaciones que realizaran en este tráfico, respecto a que los autorizan. Y la misma responsabilidad tienen los propietarios que autorizan a sus esclavos a vivir fuera de su propia casa empleándose en venta de comestibles y otras cosas porque se entiende que lo hacen con su consentimiento» ${ }^{84}$. Este tipo de regulaciones mostraban el interés y preocupación

\footnotetext{
81 González, 2011: 80-83.

82 Sánchez Valverde, 1785: 118.

83 Barickman, 1994: 653.

84 Bando de Buen Gobierno mandado a publicar por el Sr. Mariscal de Campo D. Carlos de Urrutia, Santo Domingo, 23 de abril de 1815, AGN, ARS, leg. 21.
} 
de las autoridades locales por limitar y supervisar el tiempo que los esclavos vivían sin supervisión ${ }^{85}$. La articulación de estas normativas respondía a diferentes intereses de las autoridades coloniales, entre los cuales no podemos menospreciar la existencia a un cierto temor a que se produjera un levantamiento de esclavos que pretendiera establecer vínculos con Haití o establecer la independencia de la colonia ${ }^{86}$. La rebelión de los italianos de 1810 había mostrado los nexos existentes entre las autoridades haitianas y potenciales conspiradores radicados en Santo Domingo ${ }^{87}$. El pro-haitianismo implicaba necesariamente la abolición de la esclavitud por lo que en el conjunto de rebeliones y conspiraciones que estallaron en los últimos años del periodo colonial, como sugiere Quisqueya Lora, Saint- Domingue/Haití se convirtió en el referente real o imaginado que buena parte de los conspiradores establecieron como factible ${ }^{88}$. La sombra de la anexión a Haití, y como consecuencia, la abolición de la esclavitud, fue cobrando cada vez mayor prestancia haciéndose notar con especial intensidad desde 1809, a pesar de la terrible campaña llevada a cabo por Dessalines años antes.

A pesar de ello, y dada la rentabilidad del trabajo esclavo, los amos trataron de preservar, en la medida de lo posible, los beneficios que les otorgaba la detentación del dominio. En un contexto especialmente convulso, ante la imposibilidad de adquirir un alto número de siervos, bien fuera por su alto precio, bien fuera por las estrecheces del mercado esclavista, muchos propietarios optaron por disponer, bien por vía testamentaria, bien por la compra, de pequeñas partes del dominio de un esclavo, detentando la propiedad de manera mancomunada ${ }^{89}$. Esta forma de tenencia del esclavo se intensificó durante el periodo 1809-1821, con la restitución de Santo Domingo a la soberanía española, periodo marcado por una grave crisis económica derivada del impacto de la situación vivida en la colonia desde 1795. Para los esclavos adquiridos a través de herencia, la parcialización del dominio respondía a la realidad del marco socioeconómico del propietario. Si bien ésta división de la propiedad por vía testamentaria puede ser algo ilustrativo del escaso número de que podía disponer un propietario, más trascendente nos parece que los herederos trataran de preservar estas parcialidades, impulsados, probablemen-

\footnotetext{
85 Barickman, 1994: 667.

86 Moya Pons, 2010: 78-79.

87 Eller, 2011: 105-141.

88 Lora, 2011: 134-135.

89 Testamento de D. Juan del Rosario Ruiz, El Seibo, 3 de Julio de 1798, AGN, ARS, leg. 39. En este testamento se especifica que el fallecido tenía «100 pesos en el negro Martín, mitad de su valor, y 185 pesos en la negra Lorenza».
} 
te, por la debilidad endémica del mercado de esclavos que imposibilitaba o dificultaba la capacidad de reposición a un precio razonable. En la mayoría de los casos estudiados, los propietarios tenían lazos familiares, por lo que, en última instancia, la propiedad podía ser interpretada, en un sentido amplio, como un «esclavo de la casa», que trabajaba para los componentes del núcleo familiar.

En cuanto a los compradores de estas parcialidades, en las mismas participaban un número pequeño de propietarios, dos o tres en función de la documentación consultada, con la intención de adquirir fuerza trabajo a tiempo parcial. En nuestra opinión, además de las motivaciones antes señaladas, debemos interpretar estas compras parciales en base a criterios de diversificación económica, donde invertir en la compra de ciertas cantidades parciales de dominio sobre esclavos cuya rentabilidad fuera constatada podía ser considerada una opción rentable. La inversión en la compra parcial de esclavos podía asegurar la obtención de una cantidad más o menos estable de tiempo de trabajo del esclavo o, al menos, de una parte de los réditos que el trabajo del mismo brindaba. Tiempo de trabajo del esclavo, o parte de sus jornales, en función de la cantidad de dominio obtenido en la compra, sobre la tasación del valor de mercado, eran incentivos que interesaban al menos a una parte de los propietarios. Sin embargo, esto no obstaculizaba para que, si las circunstancias y la oportunidad se presentaban, algunos de los propietarios intentaran conseguir las otras partes del dominio ${ }^{90}$. Cada propietario detentaba, exclusivamente, el dominio que había adquirido y, si no mediaba un acto de compra, herencia, donación o permuta, no podía disponer de más trabajo o jornales del esclavo de los que estuvieran establecidos. Si uno de los propietarios moría, el dominio pasaba, como cualquier otra propiedad, a sus herederos, nunca al resto de propietarios.

Este tipo de situaciones pueden ser interpretadas de manera distinta si tenemos en cuenta la perspectiva del esclavo. Así circunstancias que afectaban a su cotidianidad estaban condicionadas por la forma de tenencia del dominio,

90 Contrato de compraventa del esclavo Basilio por Severiano Serrano, El Seibo, 8 de enero de 1818, AGN, ARS, leg. 36. La compraventa se realiza por una tercera parte del valor del esclavo, cuantificado en 90 pesos. En el testamento realizado por Severiano Serrano, se especificaba entre sus bienes a «un negro llamado Basilio, me pertenecen dos partes, y la tercera, que es de 90 pesos, es de la dicha mi hermana», Testamento de Severiano Serrano, El Seibo, 24 de marzo de 1818, AGN, ARS, leg. 36. Posteriormente, en un codicilo del mismo testamento redactado meses más tarde, se expone que a la muerte de su hermana María Victoria Serrano, quedando él como único heredero, había obtenido la tercera parte de la propiedad del esclavo, por lo que era el único propietario del esclavo. Codicilo del Testamento de Severiano Serrano, El Seibo, 22 de diciembre de 1818, AGN, ARS, leg. 36. 
ya que la propiedad mancomunada representaba algunas cuestiones que la documentación no nos permite resolver. No podemos establecer, a ciencia cierta, donde residía el esclavo, si bien debía establecerse un pacto entre los propietarios que asegurara el cumplimiento de las responsabilidades adquiridas con la compra, así como un cierto grado de vigilancia. En los entornos familiares, este tipo de situaciones podían resolverse de manera satisfactoria al quedar a cargo del esclavo, en la práctica, uno de los propietarios, que debía reintegrar las partes del beneficio del trabajo al resto ${ }^{91}$. Los niños nacidos de esclavas cuya titularidad era mancomunada, recibían la misma consideración que la madre, aplicándosele la misma consideración jurídica.

La fragmentación del dominio podía abrir, si se daban las circunstancias oportunas, fisuras en cuanto a la consideración social del esclavo. En el testamento de Severiano Soriano de marzo de 1818, se concede la libertad a un esclavo llamado Basilio, «en sus dos terceras partes», que era la totalidad del dominio adquirido por este propietario en el momento de la redacción del testamento ${ }^{92}$. Este tipo de situaciones, en apariencia semejantes a las que sucedían con los esclavos coartados, tenían en realidad, notables diferencias. El esclavo coartado entregaba, de manera periódica, cantidades de dinero para alcanzar el precio de corte y pagar, de ésta forma, el valor del dominio total de su propietario. Por el contrario, en este tipo propiedad mancomunada, el esclavo debía alcanzar la libertad entendiendo el dominio de manera fragmentada, interpretando además, que cada parte tenía, por sí misma, un valor absoluto. Así, a medida que el esclavo iba adquiriendo la libertad de forma parcial, iba desprendiéndose de las cargas que tenía adquiridas con cada uno de sus propietarios de los que había quedado manumitido, sin que el resto de los amos que aún disponían de partes de su propiedad pudieran captar mayores cantidades de tiempo de trabajo o de sus jornales. Si bien primaba la consideración jurídica del esclavo, en la práctica, los esclavos que estaban bajo este tipo de circunstancias podían disponer de mayores ingresos a través de sus jornales o una mayor cantidad de tiempo que podía invertir en su propio beneficio. Así, el esclavo Basilio podía detentar dos terceras partes de sus jornales o de su tiempo de trabajo, lo que llevado al terreno de lo cotidiano implicaba que disfrutaba de la consideración de libre la mayor parte de su tiempo, quedando restringida su faceta como esclavo exclusivamente al tercio

91 Testamento de Antonio del Rosario y Mercedes, grumete de la fragata la Flora, Hospital de San Juan de Dios de Santo Domingo, 2 de octubre de 1759, AGN, ARS, leg. 51. «La mitad del importe de un negro llamado Miguel y que este lo tiene su hermano Gregorio del Rosario que tiene la otra mitad del dicho negro, y que vivían uno con otro».

92 Testamento de Severino Soriano, El Seibo, 24 de marzo de 1818, AGN, ARS, leg. 36. 
del dominio del que aún no se había liberado. Como refiere Rafael Díaz, con frecuencia la concepción de libertad y esclavitud no pueden encasillarse como entidades absolutamente distinguibles, ya que la variedad de situaciones establecidas a través de las prácticas sociales y de los pactos que rigieron la relación entre amo y esclavo, nos ofrecen un escenario de extraordinaria complejidad donde el marco jurídico de la esclavitud entraba en confrontación con las prácticas sociales imperantes ${ }^{93}$.

\section{A MODO DE RECAPITULACIÓN}

Dentro del proyecto reformista hispánico, el establecimiento una normativa homogénea en cuanto al trato de los esclavos era una premisa fundamental para el desarrollo de un gran proyecto esclavista a imagen y semejanza al que habían desarrollado franceses o británicos en el Caribe antillano. Para ello, y desde la Audiencia de Santo Domingo, trataron de establecer nuevas leyes que, con el deseo de que fueran aplicadas en el conjunto de los territorios españoles en América, sirvieran para amortiguar las posibles tensiones que el incremento del número de esclavos podía generar en las sociedades americanas. A pesar de varios intentos, esta normativa, si bien fue redactada, no fue puesta en práctica en su totalidad por varios motivos, entre ellos, el choque que se establecía con las complejas relaciones que articulaban la relación amo-esclavo, basadas en la costumbre y en una normativa legal que apenas había variado considerablemente durante el largo tiempo colonial. Ni siquiera en Santo Domingo, donde el renglón económico que ocupaba a un significativo número de esclavos era el ganadero, estas nuevas leyes pudieron aplicarse con éxito. Si bien esta legislación pretendía endurecer las condiciones de servidumbre, también trataba de establecer un papel más activo a las autoridades locales como garantes del cumplimiento de las leyes, lo que significaba, de facto, una intromisión en el dominio que ejercían los propietarios. De esta forma, las nuevas normativas tuvieron serias dificultades para ser aplicadas, tanto durante el dominio español como durante el francés en Santo Domingo. En buena medida por la actitud refractaria de los agentes sociales que, guiados por diferentes motivaciones, entorpecieron su implementación. Así, la mayor vigilancia y supervisión del tratamiento dispensado a los esclavos, que pregonaban los intentos de reforma normativos españoles, chocaban con los intereses de los propietarios, quienes temían que dicha interferencia en su capacidad de dominio pudiera generar problemas en su relación con los

93 Díaz, 2003: 67-78. 
esclavos. Porque la detentación de dominio, como hemos visto en nuestro trabajo, no siempre se alcanzaba por vía legales, abundando las apropiaciones de esclavos, intentos de re-esclavización a esclavos manumitidos o desatenciones de la obligaciones contraídas con los esclavos a través de su compra, entre otros excesos. La preservación del dominio fue una gran preocupación para los propietarios, ya que, incluso en los periodos de mayor contracción económica donde la adquisición de mano de obra esclava se contrajo, la clase propietaria articuló estrategias para seguir acaparando, si no la totalidad del trabajo del esclavo, sí algunas partes del mismo que les resultaban rentables. De otro lado, los esclavos dominicanos, si se establecían las condiciones adecuadas, disponían de cierta capacidad de acción dentro de las complejas relaciones que rigieron el tratamiento de sus amos. Ante los abusos de éstos, concurrían a las instituciones de justicia para lograr que se les tasara justamente su valor de mercado, se les reconociera por libres ante los intentos de re-esclavización, se les reconocieran las cantidades de plata entregadas a su propietario para alcanzar la libertad, o que comenzaran a exigir papel que certificara los acuerdos a los que habían llegado con sus amos. Estas estrategias se mantuvieron tanto bajo soberanía española como bajo soberanía francesa, lo que nos sugiere que existió una cierta línea de continuidad en la utilización de las instituciones de justicia por parte de los esclavos, a pesar de que durante el periodo de dominación francés se intentara socavar dicha posibilidad. El marco legal vigente ofrecía, tanto a propietarios como a esclavos, una serie de garantías y, al mismo tiempo, de resquicios, que posibilitaba la implementación de estrategias orientadas a satisfacer sus intereses, fracturando y remodelando la aplicación efectiva de las leyes esclavistas.

\section{BiBLIOGRAFÍA}

Altieri, Gerardo A. Carlo, "Derecho y esclavitud en el Puerto Rico del siglo XIX", InterCAmbio, 6/7 (San José de Costa Rica, 2009): 91-127.

Barickman, B. J., "A Little of Land that they call Roça: Slave Provisions Grounds in the Recôncavo 1780-1860", The Hispanic American Historical Review, 74/4 (Duke, Nov. 1994: 469-687.

Belmonte Postigo, José Luis, "De cómo la costumbre articula derechos. Esclavos en Santo Domingo a fines del tiempo colonial", Francisco Javier Laviña, Ricardo Piqueras y Cristina Mondéjar (eds.), Afroamérica, espacios e identidades, Barcelona, Editorial Icaria, 2013: 65-92. 
Blackburn, Robin, The Making of New World Slavery: From the Baroque to the Modern, 1492-1800, London, Verso, 1997.

Buscaglia, José, "El poder, la ideología y el terror en el Mar de las Antillas”, José Antonio Piqueras (ed.), Historia de las Antillas, vol.5, Madrid, Doce Calles, 2014: 475-517.

Cardoso, Ciro, "The peasant breach in the slave system. New Developments in Brazil”, Luso-Brazilian Review, 25/1,(Winsconsi Summer, 1988): 49-57.

De la Fuente, Alejandro, "Slaves and the Creation of Legal Rights in Cuba", Hispanic American Historical Review, 4/87 (Pittsburgh, 2007): 659-692.

De la Fuente, Alejandro, "From Slaves to Citizens? Tannenbaum and the Debates on Slavery, Emancipation and Race Relations in Latin America", International Labor and Working Class History, 77 (Cambridge, Spring 2010): 154-173.

De la Fuente, Alejandro, "Slavery and the Law: A Reply", Law and History Review, 22/2 (Cambridge, Summer 2004): 383-387.

Díaz, Rafael, “¿Es posible la libertad en la esclavitud? A propósito de la tensión entre la libertad y la esclavitud en la Nueva Granada", Historia Crítica, 24 (Bogotá, 2003): 67-74.

Eller, Anne, "All would be equal in the effort: Santo Domingo's Italian Revolution, Independence and Haiti, 1809-1822", Journal of Early American History, 1/2 (Dundee, July, 2011): 105-141.

Fergus, Claudius, "The Siete Partidas: A framework for philanthropy and coercion during the Ameriolation experiment in Trinidad, 1823-34", Caribbean Studies, 36/1 (Río Piedras, January-June, 2008): 75-89.

Freire, Jonis, "Alforrias e tamanho das posses. Possibilidades de libertade em penas, medias e grandes propiedades do sudeste escravista (século XIX)", Varia Historia, 27/45 (Belo Horizonte, 2011): 211-232.

Gelman, Jorge, "Sobre esclavos, peones, gauchos y campesinos: el trabajo y los trabajadores en una estancia rioplatense", Juan Carlos Garavaglia y Jorge Gelman (eds.), El mundo rural ríoplatense a fines de la época colonial: estudios sobre producción y mano de obra, Buenos Aires, Fundación Simón Rodríguez-Editorial Biblos, 1989: 241-280.

González, Raymundo, De esclavos a campesinos. Vida rural en Santo Domingo colonial, Santo Domingo, Archivo General de la Nación, 2011.

Gudmundson, Lowell, "Negotiating Rights under Slavery, The Slaves of San Jerónimo (Baja Verapaz, Guatemala) Confront their Dominican Masters in 1810", The Americas, 60/1 ( Berkeley, July 2003): 109-114.

Kemner, Jochem, Dunkle Gestalten. Freie farbige in Santiago de Cuba (1850-1886), Berlin, Verlag, 2010. 
Knight, Franklin, "The Disintegration of the Caribbean Slave Systems, 1772-1886", Knight, Franklin (ed.), General History of the Caribbean, Vol. 3, London and Basingstoke, UNESCO-Palgrave Macmillan, 2007: 322-345.

Laviña, Javier, "Iglesia y esclavitud Cuba", América Negra, 1 (Bogotá, 1991): 11-29.

Lora, Quisqueya, "El sonido de la libertad. 30 años de agitaciones y conspiraciones en Santo Domingo (1791-1821)", Clío, Órgano de la Academia Dominicana de Historia, 80/182 (Santo Domingo, julio-diciembre 2011): 109-140.

Lucena Salmoral, Manuel "El derecho de coartación del esclavo en la América colonial española", Revista de Indias, LIX/216 (Madrid, 1999): 357-374.

Lucena Salmoral, Manuel, Leyes para esclavos: el ordenamiento jurídico sobre la condición, tratamiento, defensa y represión de los esclavos en las colonias de la América española, Madrid, Ediciones Tavera, 2000.

Lucena Salmoral, Manuel, Los códigos negros de la América española, Alcalá de Henares, Ed. UNESCO-Universidad de Alcalá, 1996.

Malagón Barceló, Javier, Código Negro Carolino, Santo Domingo, Ediciones de Taller, 1974.

Mintz, Sidney y Handman-Xifaras, Marie-Élisabeth, "Cuba: Terre et esclaves”, Études rurales, 48 (Paris, octubre-diciembre 1972): 135-147.

Moreta Castillo, Américo, “Aspectos jurídicos del Código Negro Carolino", Revista Clío, 77/176 (Santo Domingo, 2008): 31-38.

Moya Pons, Frank, "La crisis de las Monarquías y su impacto en las Antillas", Clío, Órgano de la Academia Dominicana de Historia, 180 (Santo Domingo, julio-diciembre 2010): 55-86.

Nessler, Graham, "The Shame of the Nation. The Force of the Re-Enslavement and the Law of Slavery under the Regime of Jean Louis Ferrand in Santo Domingo 1804-1809”, New West Indian Guide, 86/1-2 (Leiden, 2012): 5-28.

Premo, Bianca, "An Equity against the Law. Slave rights and Creole Jurisprudence in Spanish America", Slavery \& Abolition, $32 / 4$ (Oxfordshire, december, 2011): 495-551.

Romano, Ruggiero, Moneda, pseudomonedas y circulación monetaria en las economías de México, México DF, Fideicomiso Historia de las Américas, 1998.

Sánchez Valverde, Antonio, Idea del Valor de la Isla Española y utilidades que de ella puede sacar su Monarquía, Madrid, Imprenta de D. Pedro Marín, 1785.

Scott, Rebecca, "Paper thin: Freedom and Re-Enslavement in the Diaspora of the Haitian Revolution", Law and History Review, 29, Special Issue 4 (Cambridge, November 2011): 1061-1087.

Scott, Rebecca, Slave Emancipation in Cuba. The Transition to Free Labor in Cuba, 1860-1899, Pittsburgh, University of Pittsburgh Press, 2000. 
Silié, Rubén, Economía, esclavitud y población. Ensayo de interpretación histórica del Santo Domingo español en el siglo XVIII, Santo Domingo, Academia Dominicana de la Historia, 2009.

Stern, Steve J., Los pueblos indígenas del Perú y los desafios de la conquista española, Madrid, Editorial Alianza, 1982.

Varella, Claudia, "El canal administrativo de los conflictos entre esclavos y amos. Causas de manumisión decididas entre Síndicos en Cuba", Revista de Indias, LXXI/251 (Madrid, 2011): 109-136

Widmer, Rudolf S, La propiedad en entredicho. Una historia documental de Higüey, siglos XVII y XVIII, Santo Domingo, Editora Manatí, 2004.

Zeuske, Michael, "Estructuras e identidad en la segunda esclavitud. Caso Cuba, 18001940”, Historia Crítica, 24 (Bogotá, julio-diciembre 2004): http://historiacritica. uniandes.edu.co/html/24/art_zeuske.html (Consultada en junio de 2012).

Fecha de recepción: 4 de enero de 2013

Fecha de aceptación: 17 de febrero de 2013

\section{Two Sides of the Same Coin. Reformism and Slavery in Santo Domingo at the End of the Colonial Period}

The Bourbon reforms tried to increase slavery in the Spanish Caribbean. One of these projects was the creation of a new Legal Code pertaining to the relationship between owners and slaves, the Ordenanzas de Santo Domingo and, later, the Código Negro Carolino. These new laws were so far removed from pre-existing owner-slave customs and traditions in Santo Domingo that they were never were implemented.

KEY WORDS: Bourbon reforms; laws; customs; slavery. 